\title{
Addendum: Using formaldehyde-assisted isolation of regulatory elements (FAIRE) to isolate active regulatory DNA
}

\author{
Jeremy M Simon, Paul G Giresi, Ian J Davis \& Jason D Lieb \\ Nat. Protoc. 7, 256-267 (2012); published online 19 January 2012; addendum published after print 13 January 2014
}

In the protocol entitled 'Using formaldehyde-assisted isolation of regulatory elements (FAIRE) to isolate active regulatory DNA, we described how to perform FAIRE from cultured cell lines and mammalian tissues ${ }^{1}$. In this addendum, we compile a list of species and cell types in which FAIRE has been successfully performed according to a published report. This survey confirms that the FAIRE protocol, typically with only minor modification, is applicable to animals, plants, fungi, protists and viruses. Please note that this survey was performed manually, and so it is possible that our list of species and publications is not complete. We apologize for any omissions. Our hope is that by compiling this list, scientists who may wish to use FAIRE in the cell types or species below may refer to the listed papers for any modifications required to our protocol. There are several notable experimental systems for which we could not find published reports of FAIRE data, including Caenorhabditis elegans, Tribolium (flour beetle), zebrafish, Xenopus and sea urchin. Although we suspect that FAIRE will be effective in these systems, it is always possible that special modifications to the FAIRE protocol will be required. If you are having trouble getting FAIRE to work in your system, we welcome any inquiries.

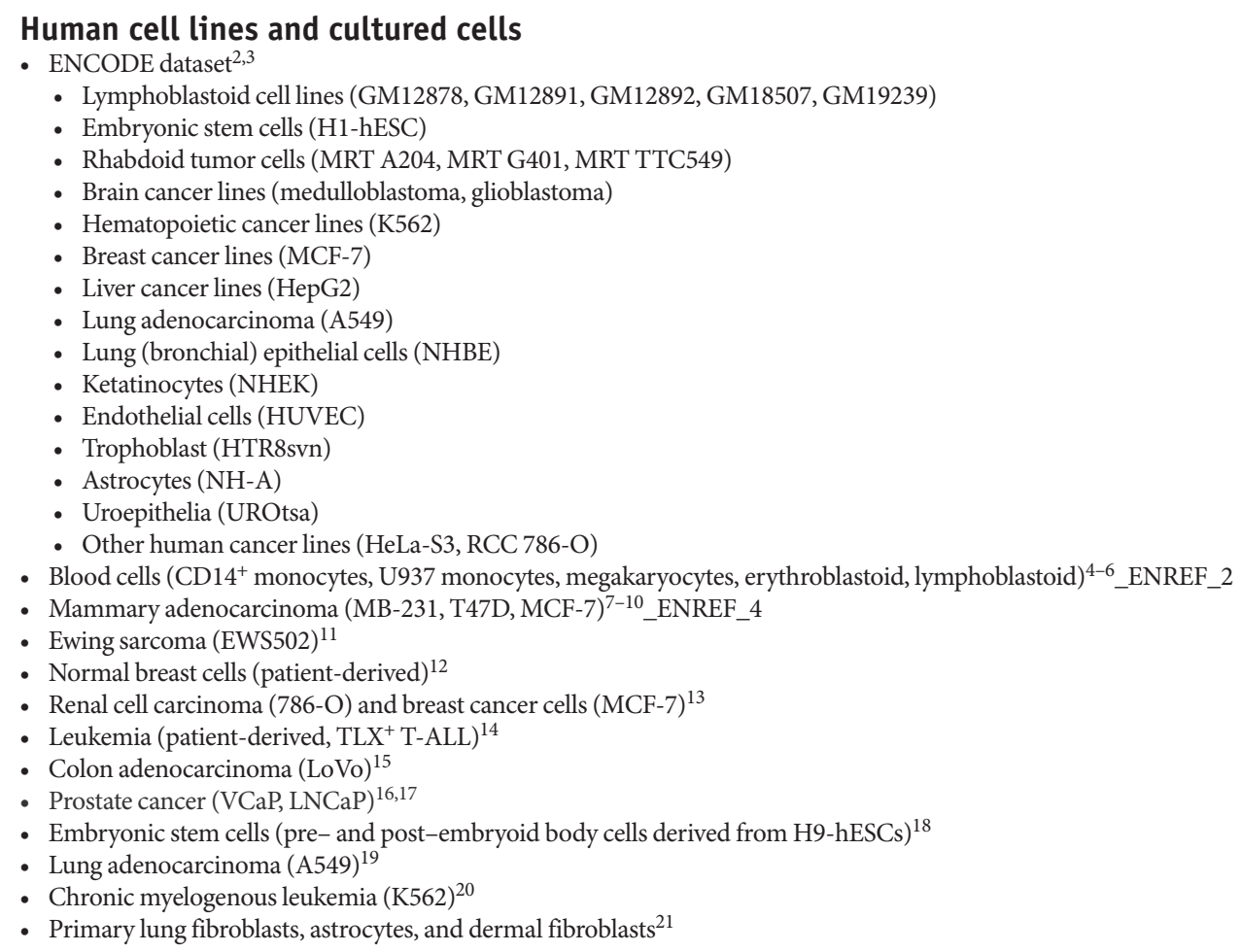

Human primary tissues and clinical samples

- Renal cell carcinoma ${ }^{22,23}$

- Pancreatic islets ${ }^{24}$

Human tissues (public data from ENCODE, not yet published)

- Colon

- Endometrium

- Frontal cortex

- Kidney

- Pancreas

- Small intestine 


\section{ADDENDA}

\section{Rat}

- Schwann cells ${ }^{25-27}$

\section{Mouse}

- Cell lines

- Bone marrow macrophages, fibroblasts (3T3), and adipocytes (3T3-L1) ${ }^{28-31}$

- Mammary adenocarcinoma (3134 cells) and anterior pituitary corticotroph (AtT-20 cells) ${ }^{32}$

- $\mathrm{T}$ cells $\left(\mathrm{CD} 4^{+/} \mathrm{CD} 8^{+}\right)^{33}$

- Fibroblasts (L929) and erythroid cells (MEL 585)_ENREF_33 (ref. 34)

- Testis embryonal carcinoma (F9 cells $)^{35}$

- Embryonic stem cells (129Sv, E14) $)^{36,37}$

- Tissue

- Liver $^{38}$

- Brain $^{39}$

\section{Drosophila}

- Cultured embryo cells (Kc cells $)^{40}$

- Embryos, appendage imaginal discs, third-instar central nervous system tissue $e^{41}$

\section{Plants}

- Maize husk tissue ${ }^{42}$

- Chlamydomonas reinhardtii ${ }^{43,44}$

- Arabidopsis thaliana ${ }^{45}$

\section{Fungi}

- Saccharomyces cerevisiae $e^{46-49}$

- Schizosaccharomyces pombe $e^{50}$

- Coprinopsis (mushroom; V. Hench and P. Pukkila, personal communication)

\section{Viruses}

- Cytomegalovirus ${ }^{51,52}$

- Kaposi sarcoma herpesvirus ${ }^{53}$

- HPV16-positive cervical carcinoma $(\mathrm{CaSki})^{54}$

\section{Protists}

- Plasmodium ${ }^{55}$

1. Simon, J.M., Giresi, P.G., Davis, I.J. \& Lieb, J.D. Using formaldehyde-assisted isolation of regulatory elements (FAIRE) to isolate active regulatory DNA. Nat. Protoc. 7, 256-267 (2012).

2. Thurman, R.E. et al. The accessible chromatin landscape of the human genome. Nature 489, 75-82 (2012).

3. Song, L. et al. Open chromatin defined by DNaseI and FAIRE identifies regulatory elements that shape cell-type identity. Genome Res. 21, 1757-1767 (2011).

4. Paul, D.S. et al. Maps of open chromatin guide the functional follow-up of genome-wide association signals: application to hematological traits. PLoS Genet. 7, e1002139 (2011).

5. Dhami, P. et al. Complex exon-intron marking by histone modifications is not determined solely by nucleosome distribution. PLoS ONE 5, e12339 (2010).

6. Smith, A.J. et al. Use of allele-specific FAIRE to determine functional regulatory polymorphism using large-scale genotyping arrays. PLoS Genet. 8, e1002908 (2012).

7. Joseph, R. et al. Integrative model of genomic factors for determining binding site selection by estrogen receptor- $\alpha$. Mol. Syst. Biol. 6, 456 (2010).

8. Denis, H. et al. Functional connection between deimination and deacetylation of histones. Mol. Cell. Biol. 29, 4982-4993 (2009).

9. Hurtado, A., Holmes, K.A., Ross-Innes, C.S., Schmidt, D. \& Carroll, J.S. FOXA1 is a key determinant of estrogen receptor function and endocrine response. Nat. Genet. 43, 27-33 (2011).

10. Eeckhoute, J. et al. Cell-type selective chromatin remodeling defines the active subset of FOXA1-bound enhancers. Genome Res. 19, 372-380 (2009).

11. Patel, M.J.M. et al. Tumor-specific retargeting of an oncogenic transcription factor chimera results in dysregulation of chromatin and transcription. Genome Res. 22, 259-270 (2012).

12. Bojesen, S.E. et al. Multiple independent variants at the TERT locus are associated with telomere length and risks of breast and ovarian cancer. Nat. Genet. 45, 371-384, 384e371-372 (2013).

13. Schodel, J. et al. Common genetic variants at the 11q13.3 renal cancer susceptibility locus influence binding of HIF to an enhancer of cyclin D1 expression. Nat. Genet. 44, 420-425, S421-422 (2012).

14. Dadi, S. et al. TLX homeodomain oncogenes mediate T cell maturation arrest in T-ALL via interaction with ETS1 and suppression of TCR $\alpha$ gene expression. Cancer Cell 21, 563-576 (2012).

15. Yan, J. et al. Transcription factor binding in human cells occurs in dense clusters formed around cohesin anchor sites. Cell 154, 801-813 (2013).

16. Sahu, B. et al. FoxA1 specifies unique androgen and glucocorticoid receptor binding events in prostate cancer cells. Cancer Res. 73, 1570-1580 (2013).

17. Seo, W.Y. et al. CCAR1 promotes chromatin loading of androgen receptor (AR) transcription complex by stabilizing the association between AR and GATA2. Nucleic Acids Res. 41, 8526-8536 (2013).

18. Albini, S. et al. Epigenetic reprogramming of human embryonic stem cells into skeletal muscle cells and generation of contractile myospheres. Cell Rep. 3, 661-670 (2013).

19. Bittencourt, D. et al. G9a functions as a molecular scaffold for assembly of transcriptional coactivators on a subset of glucocorticoid receptor target genes. Proc. Natl. Acad. Sci. USA 109, 19673-19678 (2012).

20. Dhami, P. et al. Genomic approaches uncover increasing complexities in the regulatory landscape at the human SCL (TAL1) locus. PLoS ONE 5, e9059 (2010). 


\section{ADDENDA}

21. Markovics, J.A. et al. Interleukin- $1 \beta$ induces increased transcriptional activation of the transforming growth factor- $\beta$-activating integrin subunit $\beta 8$ through altering chromatin architecture. J. Biol. Chem. 286, 36864-36874 (2011).

22. Simon, J.M. et al. Variation in chromatin accessibility in human kidney cancer links H3K36 methyltransferase loss with widespread RNA processing defects. Genome Res. doi:10.1101/gr.158253.113 (2013).

23. Buck, M.J. et al. Alterations in chromatin accessibility and DNA methylation in clear cell renal cell carcinoma. Oncogene doi:10.1038/onc.2013.455 (2013).

24. Gaulton, K.J.N. et al. A map of open chromatin in human pancreatic islets. Nat. Genet. 42, 255-259 (2010).

25. Jagalur, N.B. et al. Functional dissection of the 0ct6 Schwann cell enhancer reveals an essential role for dimeric Sox10 binding. J. Neurosci. 31, 8585-8594 (2011).

26. Jones, E.A. et al. Regulation of the PMP22 gene through an intronic enhancer. J. Neurosci. 31, 4242-4250 (2011).

27. Jones, E.A. et al. Distal enhancers upstream of the Charcot-Marie-Tooth type 1A disease gene PMP22. Hum. Mol. Genet. 21, 1581-1591 (2012).

28. Lefterova, M.I. et al. Cell-specific determinants of peroxisome proliferator-activated receptor $\gamma$ function in adipocytes and macrophages. Mol. Cell. Biol. 30, 20782089 (2010).

29. Ghisletti, S. et al. Identification and characterization of enhancers controlling the inflammatory gene expression program in macrophages. Immunity 32, 317-328 (2010).

30. Waki, H. et al. Global mapping of cell type-specific open chromatin by FAIRE-seq reveals the regulatory role of the NFI family in adipocyte differentiation. PLoS Genet. 7, e1002311 (2011).

31. Cristancho, A.G. et al. Repressor transcription factor 7-like 1 promotes adipogenic competency in precursor cells. Proc. Natl. Acad. Sci. USA 108, 16271-16276 (2011).

32. Wiench, M. et al. DNA methylation status predicts cell type-specific enhancer activity. EMBO J. 30, 3028-3039 (2011).

33. Koch, F. et al. Transcription initiation platforms and GTF recruitment at tissue-specific enhancers and promoters. Nat. Struct. Mol. Biol. 18, 956-963 (2011).

34. Anguita, E., Villegas, A., Iborra, F. \& Hernandez, A. GFI1B controls its own expression binding to multiple sites. Haematologica 95, 36-46 (2010).

35. Yaragatti, M., Basilico, C. \& Dailey, L. Identification of active transcriptional regulatory modules by the functional assay of DNA from nucleosome-free regions. Genome Res. 18, 930-938 (2008).

36. Tiwari, V.K. et al. Target genes of topoisomerase II $\beta$ regulate neuronal survival and are defined by their chromatin state. Proc. Natl. Acad. Sci. USA 109, E934-E943 (2012).

37. Wallmen, B., Schrempp, M. \& Hecht, A. Intrinsic properties of Tcf1 and Tcf4 splice variants determine cell-type-specific Wnt/ $\beta$-catenin target gene expression. Nucleic Acids Res. 40, 9455-9469 (2012).

38. Takeda, Y., Kang, H.S., Angers, M. \& Jetten, A.M. Retinoic acid-related orphan receptor $\gamma$ directly regulates neuronal PAS domain protein 2 transcription in vivo. Nucleic Acids Res. 39, 4769-4782 (2011).

39. Abuhatzira, L., Shamir, A., Schones, D.E., Schaffer, A.A. \& Bustin, M. The chromatin-binding protein HMGN1 regulates the expression of methyl CpG-binding protein 2 (MECP2) and affects the behavior of mice. J. Biol. Chem. 286, 42051-42062 (2011).

40. Filion, G.J. et al. Systematic protein location mapping reveals five principal chromatin types in Drosophila cells. Cell 143, 212-224 (2010).

41. McKay, D.J. \& Lieb, J.D. A common set of DNA regulatory elements shapes Drosophila appendages. Dev. Cell 27, 306-318 (2013).

42. Louwers, M. et al. Tissue- and expression level-specific chromatin looping at maize b1 epialleles. Plant Cell 21, 832-842 (2009).

43. Strenkert, D., Schmollinger, S., Sommer, F., Schulz-Raffelt, M. \& Schroda, M. Transcription factor-dependent chromatin remodeling at heat shock and copperresponsive promoters in Chlamydomonas reinhardtii. Plant Cell 23, 2285-2301 (2011).

44. Vischi Winck, F. et al. Genome-wide identification of regulatory elements and reconstruction of gene regulatory networks of the green alga Chlamydomonas reinhardtii under carbon deprivation. PLOS ONE 8, e79909 (2013).

45. Omidbakhshfard, M.A., Wink, F.V., Arvidsson, S., Riaño-Pachón, D.M. \& Mueller-Roeber, B. A step-by-step protocol for formaldehyde-assisted isolation of regulator elements (FAIRE) from Arabidopsis thaliana. J. Integr. Plant Biol. doi:10.1111/jipb.12151 (2013).

46. Nagy, P.L., Cleary, M.L., Brown, P.O. \& Lieb, J.D. Genome-wide demarcation of RNA polymerase II transcription units revealed by physical fractionation of chromatin. Proc. Natl. Acad. Sci. USA 100, 6364-6369 (2003).

47. Hogan, G.J., Lee, C.-K. \& Lieb, J.D. Cell cycle-specified fluctuation of nucleosome occupancy at gene promoters. PLoS Genet. 2, e158 (2006).

48. Berchowitz, L.E., Hanlon, S.E., Lieb, J.D. \& Copenhaver, G.P. A positive but complex association between meiotic double-strand break hotspots and open chromatin in Saccharomyces cerevisiae. Genome Res. 19, 2245-2257 (2009).

49. Lee, K. et al. Genetic landscape of open chromatin in yeast. PLoS Genet. 9, e1003229 (2013).

50. Wilhelm, B.T. et al. Differential patterns of intronic and exonic DNA regions with respect to RNA polymerase II occupancy, nucleosome density and H3K36me3 marking in fission yeast. Genome Biol. 12, R82 (2011).

51. Nitzsche, A., Paulus, C. \& Nevels, M. Temporal dynamics of cytomegalovirus chromatin assembly in productively infected human cells. J. Virol. 82, 11167-11180 (2008).

52. Rossetto, C.C., Tarrant-Elorza, M. \& Pari, G.S. Cis- and trans- acting factors involved in human cytomegalovirus experimental and natural latent infection of CD14 ${ }^{+}$ monocytes and CD34+ cells. PLoS Pathog. 9, e1003366 (2013).

53. Hilton, I.B. et al. The open chromatin landscape of Kaposi's sarcoma-associated herpesvirus. J. Virol. 87, 11831-11842 (2013).

54. De-Castro Arce, J., Gockel-Krzikalla, E. \& Rosl, F. Silencing of multi-copy HPV16 by viral self-methylation and chromatin occlusion: a model for epigenetic virus-host interaction. Hum. Mol. Genet. 21, 1693-1705 (2012).

55. Ponts, N. et al. Nucleosome landscape and control of transcription in the human malaria parasite. Genome Res. 20, $228-238$ (2010). 